\title{
THE BEHAVIOR OF COLLOIDAL SUSPENSIONS WITH IMMISCIBLE SOLVENTS
}

BY W. LASH MILLFR AND R. H. MCPHERSON ${ }^{1}$

Now that the study of colloids is attracting general interest, and convenient methods have been devised for the preparation of colloidal solutions in solvents other than water, it seems desirable to study the behavior of such solutions when brought together, with a view to discovering, if they exist, cases of equilibrium analogous to the distribution of iodine between ether and water. ${ }^{2}$

The prevalent theory of colloidal solutions, which represents them as finely divided suspensions in an inert liquid, seems at first sight to negative the possibility of any such distribution. Graham's experiments ${ }^{3}$ however, and the more recent work of Linder and Picton" show that many colloids possess the power of diffusion, i. e., that their chemical potential increases with increase of their concentration $;^{5}$ and as, from the point of view of the phase rule, a suspension whose potential depends on its concentration cannot be distinguished from the constituent of a "true" solution, the phenomena of distribution may as legitimately be expected in one case as in the other. Where the change of potential with the concentration is slight, $i$. e., where the osmotic pressure is small (or the "molecular weight" of the solute or suspension is high), as in the case of the colloids, very slight differences in the properties-surface tension, dielectric constant (Perrin)of the solvent might be sufficient to offset considerable changes

${ }^{1}$ Read before the section for Physical Chemistry of the American Chemical Society, June, Igo8.

$2 \mathrm{Mr}$. Manning finds that tannin is distributed between water and ether, ethyl acetate, amyl alcohol, etc; the solutions have measurable osmotic pressure, however, and for other reasons tannin cannot be considered to be a typical colloid.

${ }^{3}$ Phil. Trans., I861, I 83; fully abstracted in Jahresber, I861, 62-82.

4 Jour. Chem, Soc., 6r, 137 (1892).

5 The theory advocated by Perrin, which endows the colloid particles with electrical charges, leads to the same conclusion. 
in concentration; so that one would expect the distribution to be very one sided, and measurable only under special conditions. These considerations suggest that instances of the distribution of colloids between two solvents are most apt to be discovered by working with colloids of marked diffusibility, and with "immiscible solvents" of almost identical composition-such as the 'critical solutions' in two component systems (phenol, water) or the two phases at the plait point of the binodal curve in three component systems (water, chloroform, alcohol, etc.).

The experiments of Winkelblech on colloids and immiscible solvents made the probability of realizing the ideas set out in the preceding paragraph seem somewhat remote. In a paper published in $1906^{1}$ that author describes " a hitherto unknown reaction for dissolved colloids" which consists in shaking the colloidal solution with petroleum, benzene, chloroform, carbon disulphide, or other immiscible solvent, whereupon the colloidal coagulates and collects in the emulsion which is formed at the surface of separation of the two solvents: This reaction leads to a delicate method for the quantitative determination of gelatine, and succeeds also with glutin, albumen, tannic acid, soluble starch, soap, wine, beer, water-glass, alkaline solutions of colophonium and of sulphur, and solutions of silicic acid in ammonia.

This reaction, if general, would make the experimental study of equilibrium in heterogeneous systems involving colloidal solutions difficult if not impossible. Winkelblech himself, however, has discussed an exception: shaking gelatine solutions with ether does not produce coagulation-and it seemed possible that among the colloidal suspensions (none of which were studied by Winkelblech) others might be found.

\section{Silver, water, isobutyl or amyl alcohol}

Our first experiments were tried with colloidal metals prepared by the methods of Bredig ${ }^{2}$ and of Svedberg. ${ }^{3}$ Silver

1 Zeit. angew. Chem., 19, 1953 (rgo8).

2 Zeit. phys. Chem., 32, I27 (I902).

a Ber. chem. Ges., 38, 3616 (1905). 
hydrosol is completely coagulated by shaking with commercial amyl alcohol or with isobutyl alcohol (traces of either of which much reduce the surface-tension of water); shaking however is necessary, merely pouring a layer of the alcohol over the hydrosol does not cause coagulation.

The 'isobutylalcosol' and 'amylalcosol' of silver by shaking with water, likewise are completely coagulated.

\section{Silver, water, phenol}

When phenol liquefied by a few drops of water is added to the hydrosol and a homogeneous solution formed by warming, no coagulation takes place even on standing; but if the solution is allowed to cool until it becomes milky from separation into two layers, and is then warmed again until homogeneous, all the silver is precipitated.

These experiments, while not resulting as had been hoped, show the dependence of the Winkelblech effect on the formation of surface, $i$. e., on capillary forces, and serve to connect it with the separation of fibrin from blood by 'whipping' and with the formation of scum on the surface of streams near waterfalls and rapids.

\section{Silver, water, chloroform, alcohol}

When silver hydrosol is shaken with chloroform, very little coagulation takes place and none of the silver goes into the chloroform. Reciprocally, water does not attract silver from the 'chloroformsol.'

On adding alcohol to the systems: hydrosol-chloroform or chloroformsol-water, and shaking to secure equilibrium, most of the silver is coagulated, and what remains in suspension is retained by the layer of liquid in which it was originally present. The chloroform may be replaced by carbon tetrachloride and the silver by gold, without materially modifying the result. These observations seem important, but as it was not found possible to prepare metallic suspensions in chloroform or carbon tetrachloride free from tarry matter, too much stress must not be laid on them. 


\section{Arsenic trisulphide, water, ehloroform, alcohol}

This system is distinguished from the last by the much greater stability of the colloid; the hydrosol may be shaken with chloroform in presence or absence of alcohol, and homogeneous solutions may be "split" or rendered heterogeneous by addition of water or of chloroform without coagulation ensuing. It consequently seemed more suitable for the object in view, and the work with colloidal metals was discontinued.

In the preliminary experiments, whenever two liquid layers were formed the arsenious sulphide was always contained exclusively in the upper layer, no matter what the proportions of the reagents (aqueous solution of arsenious acid, hydrogen sulphide water, alcohol, chloroform). If distribution was to be observed at all, it was therefore necessary to find the proportions in which water chloroform and alcohol must be mixed to give two liquid layers of almost identical composition.

\section{Determination of the binodal eurve, tie-lines and plait-point}

The system water-chloroform-alcohol has been studied by Bancroft ${ }^{1}$ to whom in fact is due most of our experimental knowledge of similar equilibria; the data for the curve plotted in Fig. I, however, were not taken from his measurements which were carried out in a thermostat at $20^{\circ}$, but were obtained directly by a series of determinations made without special precautions at room temperature. The abscissae give the volumes of chloroform (and hence of water, the sum in every case being $\mathrm{IO} \mathrm{cc}$ ) and the ordinates the volumes of alcohol needed to produce homogeneity. The curve so obtained is the "binodal curve" of Schreinemakers.

When the volume of chloroform used was $3 \mathrm{cc}$ or less, addition of alcohol caused the lower layer to gradually grow less and finally to disappear; when $4 \mathrm{cc}$ or more was used, the upper layer disappeared. The abscissa of the "plait-

${ }^{1}$ Phys. Review, 3, I20 (I895). 
point " therefore must lie between 3 and 4 . To find its position more accurately, $3.5 \mathrm{cc}$ chloroform and $6.5 \mathrm{cc}$ water were mixed in a tall cylinder of 25 ce capacity graduated in $\mathrm{I} / \mathrm{Io} \mathrm{cc}$, alcohol was added from a burette, and, after shaking, the volumes of the two phases were read (see Table 2). Then, through the point in Fig. I which represents the total com-

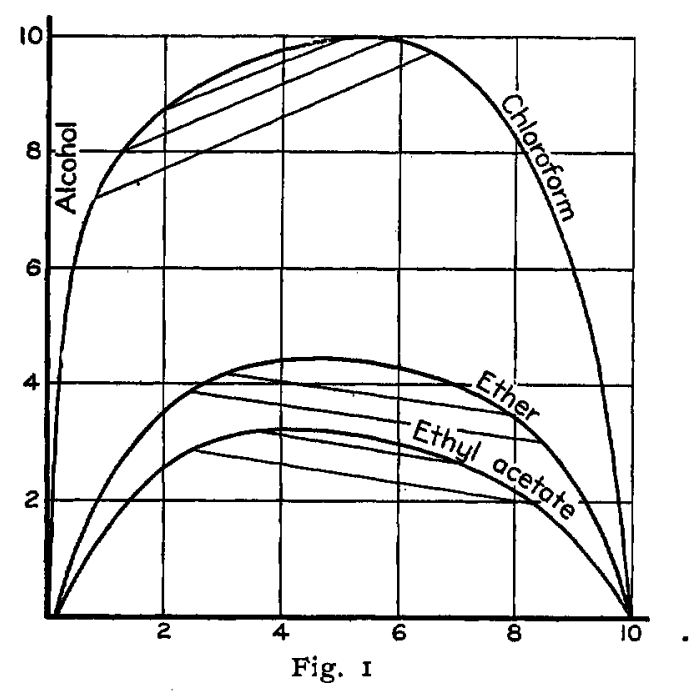

position of the system, a straight line was drawn terminated at either end by the binodal curve, its direction being so chosen that the lengths of the two portions (to right and left of the abscissa 3.5) stood in the proportion of the volumes of the upper and lower liquid layer respectively.

If in place of the volumes of the two layers their weights had been determined-or what is the same thing, if their specific gravities were the same--.the line so drawn would be a "tie-line" and its extremities would give the compositions of the two phases in equilibrium. Near the plait-point the compositions and consequently the densities of the two liquids are almost identical; lower down in the figure the graph gives only a first approximation to the compositions, 
which might be improved by introducing the densities calculated from the approxinlately known compositions of the two layers and the densities of alcohol water and chloroform, neglecting contraction on mixing.

The position of the "plait-point," $i$. e., the composition of the system in which the two layers of liquid are almost identical in composition, was found graphically, and checked by direct experiment : it is chloroform $3.5 \mathrm{cc}$, water $6.5 \mathrm{cc}$, alcohol $9.8 \mathrm{cc}$.

\section{Arsenic trisulphide, water, chloroform, alcohol, near the plait-point}

Solutions were then made up containing $5.5 \mathrm{cc}$ chloroform, $4.5 \mathrm{cc}$ "water" (i.e., $4.5 \mathrm{cc}$ altogether of the solutions of arsenious acid and hydrogen sulphide in various proportions) and alcohol in quantity almost sufficient to make a homogeneous solution. The actual amount of alcohol needed depends on the temperature and also no doubt on the excess of arsenious acid or of hydrogen sulphide present, but it was not far from $9.6 \mathrm{cc}$. In no case was distribution observed; the sulphide always remained altogether in the upper layer, although in one experiment the compositions of the two phases were so nearly identical that partial separation was effected only by five minutes whirling in a good centrifuge (Io inch arm, 2000 rev. per minute) while complete separation needed a quarter of an hour. In this experiment the total volume was I $_{5} \mathrm{cc}$, and the volumes of the two phases after separation were almost exactly equal; addition of less than $1 / 600.02 \mathrm{cc}$ of alcohol made the whole homogeneous.

To ascertain whether the arsenious sulphide renained in the upper layer because of some "passive resistance," pairs of solutions-upper and lower-were made up from the data of Fig. I, using pure water in the preparation of the "upper" and the solutions of arsenious acid and hydrogen sulphide in the preparation of the "lower" layers. On mixing, while the volumes of the two layers remained unaltered, the arsenious sulphide passed completely from the 
lower to the upper layers. "Passive resistances" therefore cannot be invoked to explain the very one sided distribution observed.

The slight difference in composition and properties of the two liquids evidently determined the distribution of the arsenious sulphide at equilibrium, from which it follows that the influence of the concentration of the latter on its chemical potential must be slight indeed--a calculation based on Perrin's theory and on measurements of the dielectric constants of the boundary solutions near the plait-point might lead to a lower limit for the 'molecular weight' of the sulphide.

\section{Arsenic trisulphide, water, chloroform, acetone}

The alcohol of the preceding sections was replaced by acetone; but, as before, the arsenious sulphide remained in the upper layer until the last drop of acetone removed the heterogeneity. The composition at the plait-point is: water $2.9 \mathrm{cc}$, chloroform I.O cc, acetone 8. I cc.

\section{Arsenic trisulphide, water, ether, alcohol}

Tables I and 2 and Fig. I give the data for the binodal curve, tie-lines and plait-point. A glance at Fig. I shows that the ether curve is much flatter, $i$. e., that in the system ether-water-alcohol, addition of a drop of alcohol produces more change in the compositions of the two layers than it does in the system chloroform-water-alcohol. To approach the plait-point by rough and ready methods is therefore much easier when chloroform is used than with ether; and from this point of view the latter system seem even less likely to afford instances of distribution than the former.

As a matter of fact, however, distribution was readily observed over a fairly wide range of composition on either side of the abscissa of the plait-point. The experiments were carried out by mixing measured volumes of I percent arsenious acid solution, ether, alcohol, and sulphuretted hydrogen water (either old or freshly prepared) in the order given, taking somewhat less alcohol than was necessary to make a 
homogeneous solution, and then adding more alcohol drop by drop, shaking, and letting stand until the two layers separated. As each drop of alcohol was added and the two layers approached otle another in composition, the amount of arsenious sulphide in the upper layer increased until the colors of the two layers were almost equal. More of the sulphide went into the upper layers, other things being equal, when excess of hydrogen sulphide was used; but even with a considerable excess of arsenic (recognized by coagulating the sulphide with a drop of hydrochloric acid, filtering, and treating separate portions of the filtrate with arsenious acid and with hydrogen sulphide respectively) the distribution was easily observable.

Left to themselves, such two layered systems with distributed sulphicle may remain for days apparently unchanged; but it was generally observed that sooner or later the upper layer lost its yellow color.

The upper layer is a very clear yellow with a touch of orange, and none of that milkiness usually observed with colloidal solutions; in this respect it resembles Linder and Picton's Arsenious sulphide $\delta$ which gave no Tyndall effect; the lower layer was almost equally clear. It is, in fact, only with such clear solutions that distribution was observed; if ether and alcohol were added to the ordinary boiled arsenious sulphide hydrosol, which relatively speaking is quite turbid, the sulphirde remained in the lower layer until the last drop of alcohol made the whole homogeneous. By adding ether to a two-layered system, the volume of the lower layer may be diminished and the arsenious sulphide in it concentrated. When the concentration reaches a certain point, depending on the composition of the system, a trace of cloudiness may be detected, which increases with further addition of ether; the color at the same time changes from orange-yellow to a more lemon-yellow tint. It is thus possible to pass gradually, or 'continuously' so to speak, from perfectly clear to almost opaque colloidal solutions. Any one of these may be brought to the plait-point by adding alcohol and water in suitable 
quantities, distribution becoming less as the clarity of the solution diminishes.

The distribution of arsenic and sulphur between the two phases has not yet been studied; it is possible that even when arsenious acid and hydrogen sulphide have been added in equivalent quantities the upper layer may contain more sulphur than is equivalent to the arsenic it contains. Nor has the effect (if measurable) of the sulphide on the composition of the systen at the plait-point, or on the temperature at which a system of given composition becomes homogeneous, been determined. These matters, together with a quantitative investigation of the effect of hydrogen sulphide on the distribution ratios will be taken up in this laboratory during the coming winter.

\section{Arsenic trisulphide, water, ether, acetone}

The composition at the plait-point is about: water $4 \mathrm{cc}$, ether $5 \mathrm{cc}$, acetone $8 \mathrm{cc}$. Distribution was observed.

\section{Arsenic trisulphide, water, ethyl acetate, alcohol}

See Tables $I$ and 2 and Fig. I. Distribution may be observed here also, though not so readily as when ether is employed. The observations are interfered with by the saponification of the acetate, which may render a heterogeneous system homogeneous on standing.

Arsenic trisulphide, water, ethyl acetate, propyl alcohol

The composition at the plait-point is about: water $12 \mathrm{cc}$, ethyl acetate $5 \mathrm{cc}$, propyl alcohol $7 \mathrm{cc}$. Distribution was observed.

\section{Antimony trisulphide, water, ether, alcohol}

A dilute solution of tartar emetic was substituted for the arsenious acid. Distribution was observed; after a few days the upper layer had become colorless, and finally all the antimony sulphide subsided from both layers.

\section{Antimony trisulphide, water, chloroform, alcohol}

No distribution was observed; the sulphide remains in the upper layer as is the case with arsenious sulphide. We 
intend to carry out similar experiments with benzene, carbon disulphide, etc., to see whether these substances resemble chloroform from this point of view.

\section{Copper sulphide, water, ether, alcohol}

A very dilute solution of copper acetate was used in place of the arsenious acid. No distribution was observed, the sulphide rmaining in the lower layer although the plaitpoint was approached very closely. This agrees with Linder and Picton's opinion that colloidal solutions of copper sulphide are much further removed from the state of 'true' solution than are those of arsenious sulphide.

\section{Summary}

The occurrence of distribution of colloids between two immiscible solvents is not a priori impossible either from the point of view of the phase rule or from that of the electrified suspension theory of colloidal solutions. It may probably be easiest observed in the case of colloids with marked power of diffusion, and "immiscible solvents" which approach each other closely in properties and composition such as those near the 'critical solution temperature' in two component systems, or the solutions at the plait-point of the binodal curve in three component systems.

The Winkelblech effect interferes with the observation of such cases of equilibrium, for instance in the case of silver hydrosol and phenol, amyl alcohiol, or isobutyl alcohol. Two experiments show the dependence of the Winkelblech effect on capillary forces.

Chloroform and alcohol do not coagulate the hydrosol of arsenious sulphide; but no distribution was observed even at the plait-point; this is not due to 'passive resistance.' The same is true when the alcohol is replaced by acetone; but if ether or ethyl acetate be substituted for the chlorcform distribution readily occurs, whether the consolute liquid be alcohol, acetone, or propyl alcohol.

In this connection a rapid method of approximately 
determining the binodal curve, tie-lines, and plait-point is described.

Antimony trisulphide, like the sulphide of arsenic, distributes between the two liquid phases in the system waterether-alcohol, but not in the system water-chloroform-alcohol.

Copper sulphide does not distribute in the system 'waterether-alcohol.

TABLE I

Binodal Curves, Room Temperature

\begin{tabular}{|c|c|c|c|c|c|c|}
\hline $\begin{array}{l}\text { Water } \\
\text { cc }\end{array}$ & $\begin{array}{l}\text { Chloro- } \\
\text { form } \\
\text { ce }\end{array}$ & $\begin{array}{c}\text { Alcohol } \\
\text { cc }\end{array}$ & $\begin{array}{l}\text { Ether } \\
\text { cc }\end{array}$ & $\begin{array}{l}\text { Alcohol } \\
\text { cc }\end{array}$ & $\begin{array}{l}\text { Ethyl } \\
\text { acetate } \\
\text { cc }\end{array}$ & $\begin{array}{c}\text { Alcohol } \\
\text { cc }\end{array}$ \\
\hline $9 \cdot 5$ & 0.5 & 6.3 & - & - & - & - \\
\hline 9 & I & $7 \cdot 7$ & - & - & $\mathbf{I}$ & I. 2 \\
\hline 8 & 2 & 8.7 & 2 & 3.5 & 2 & 2.7 \\
\hline 7 & 3 & 9.4 & 3 & $4 \cdot 2$ & 3 & $3 \cdot I$ \\
\hline 6 & 4 & 9.8 & 4 & 4.4 & 4 & 3.05 \\
\hline 5 & 5 & 9.9 & 5 & $4 \cdot 4$ & 5 & $3 \cdot I$ \\
\hline 4 & 6 & 10.0 & 6 & 4.2 & 6 & 2.9 \\
\hline 3 & 7 & 9.4 & 7 & 4.0 & 7 & 2.7 \\
\hline 2 & 8 & 8.2 & 8 & $3 \cdot 5$ & 8 & 2.2 \\
\hline I & 9 & 6.0 & 9 & 2.4 & 9 & I. 4 \\
\hline
\end{tabular}

TABLE 2

Tie-Lines

\begin{tabular}{|c|c|c|c|c|c|c|c|c|}
\hline \multicolumn{3}{|c|}{ Water, $6.5 \mathrm{cc} ; \mathrm{Chl}, 3.5 \mathrm{cc}$} & \multicolumn{3}{|c|}{ Water, $5 \mathrm{cc}$; Ether, $5 \mathrm{cc}$} & \multicolumn{3}{|c|}{$\begin{array}{l}\text { Water, } 5.5 \mathrm{cc} \text {; } \\
\text { Et. acet., } 4.5 \mathrm{cc}\end{array}$} \\
\hline $\begin{array}{l}\text { Alcohol } \\
\text { cc }\end{array}$ & $\begin{array}{l}\text { Lower } \\
\text { cc }\end{array}$ & Upper & $\begin{array}{l}\text { Alcohol } \\
\text { cc }\end{array}$ & $\begin{array}{c}\text { Lower } \\
\text { cc }\end{array}$ & Upper & $\begin{array}{l}\text { Alcohol } \\
\text { cc }\end{array}$ & $\begin{array}{l}\text { Lower } \\
\text { cc }\end{array}$ & $\underset{\text { cc }}{\text { Upper }}$ \\
\hline 8.4 & 8.5 & $9 \cdot 7$ & 2.0 & 6.6 & 5.0 & 2.5 & 6.7 & 5.6 \\
\hline 9.0 & 9.0 & 9.7 & 2.5 & 6.8 & 5.2 & 3.0 & 6.9 & $5 \cdot 9$ \\
\hline 9.4 & $9 \cdot 7$ & $9 \cdot 4$ & $\begin{array}{l}3 \cdot 5 \\
4 \cdot 0\end{array}$ & $\begin{array}{l}7.6 \\
8.3\end{array}$ & $\begin{array}{l}5.3 \\
5.0\end{array}$ & 二 & - & 二 \\
\hline
\end{tabular}

The University of Toronto, June, 1908 . 